\title{
Educação em Saúde em Moradia Universitária: Abordagem Integral da Vulnerabilidade dos Sujeitos
}

\author{
Érique José Peixoto de Miranda ${ }^{1}$ \\ Magdaeli Costa Amorim ${ }^{2}$ \\ Kátia Stancato ${ }^{3}$
}

Recebido em: 19/01/07

Aprovado em: 25/05/07

\begin{abstract}
Resumo: Voltado a atender estudantes de graduação e pós-graduação de baixa renda da Universidade Estadual de Campinas (Unicamp), o Programa de Moradia Estudantil (PME) abriga cerca de 1.000 moradores que apresentam vulnerabilidade a problemas de saúde relevantes do ponto de vista da atenção pública primária. Objetiva-se com esta pesquisa uma proposta de educação em saúde calcada na participação que partirá da realização de um censo sobre saúde dos moradores por meio de um questionário estruturado que engloba assuntos abordados no nível primário do Sistema Único de Saúde. Os dados serão trabalhados de forma descritiva a fim de guiar a intervenção. Caso necessário, encaminhamentos a outros serviços de saúde serão realizados. Espera-se, ao final do trabalho, encontrar um perfil socioeconômico condizente com a SUS-dependência e uma prevalência de agravos e doenças semelhantes aos números do Brasil.
\end{abstract}

Palavras-chave: educação em saúde, integralidade, estudantes, estudo transversal.

Health education in university student housing:

a complete approach to the vulnerability of the subjects.

Abstract: The Student Housing Program of the Campinas State University (Unicamp) shelters about 1,000 low-income under-graduate and masters degree students vulnerable to health problems, mainly in public primary health-care. The purpose of this research is to propose a form of health education based on the participation of subjects and researches through a health census of the housing residents, carried out through a structured questionnaire on topics of the primary level Brazilian Public Health System. The data will be analyzed descriptively in order to guide the intervention. If necessary, students will be directed to other health services. At the end of this research, we expect to find a social and economic profile similar to the low-income part of the Brazilian population that depends on public health systems and a prevalence of diseases similar to the numbers found in the country.

Key Words: health education; integrality; students; cross-sectional study.

\footnotetext{
${ }^{1}$ Graduando em Medicina da Faculdade de Ciências Médicas da Unicamp. E-mail:erique@ fcm.unicamp.br.

${ }^{2}$ Graduada em Comunicação Social pela Puccamp /Assessora dos Conselhos Consultivo e Deliberativo e responsável pela Área de Divulgação e Publicações do Programa de Moradia Estudantil (PME) da Unicamp. E-mail:magdaelei@unicamp.br.

${ }^{3}$ Profa. Dra. Depto. de Enfermagem da Faculdade de Ciências Médicas da Unicamp / Coord. Executiva do PME da Unicamp. E-mail: kátia@fcm.unicamp.br.
} 


\section{INTRODUÇÃO}

A Moradia Estudantil da Universidade Estadual de Campinas (Unicamp), localizada a $6 \mathrm{~km}$ do campus, na Vila Santa Izabel, distrito de Barão Geraldo, Campinas (SP), ocupa uma área de 55 mil metros quadrados, dos quais 22 mil são de área construída. No total, são 226 casas com capacidade para quatro estudantes, 27 estúdios destinados a casais e filhos, 13 salas de estudo, quatro centros de convivência e um campo de futebol, o que significa uma população de cerca de 1.000 moradores selecionados conforme critérios socioeconômicos anualmente pelo Serviço de Apoio ao Estudante (SAE) da instituição. (UNICAMP, 2006).

Voltado a estudantes de graduação e pós-graduação regularmente matriculados na Unicamp os quais não têm condições de pagar por moradia em Campinas, o Conjunto Residencial Universitário, projetado pelo arquiteto Joan Villá, começou a ser construído em 1989 e foi finalizado em 1990, sendo inaugurado no mesmo ano pelo então reitor, professor doutor Carlos Alberto Vogt. Em 4 de dezembro de 2001, foi criado através da Deliberação Consu-A-24/01 o Programa de Moradia Estudantil, órgão ligado à Reitoria da Unicamp, para aprimorar o que vinha funcionando como residência estudantil desde 1989.

Não há estudos sobre o perfil socioeconômico dos moradores do PME publicados na literatura da área de saúde. Quanto ao perfil dos estudantes que se submeteram ao vestibular nacional da Unicamp, dos 50.549 inscritos no concurso de 2004 são, em sua maioria, jovens $(60,48 \%$ deles têm até 18 anos), solteiros $(95,38 \%)$, frequientaram somente escolas públicas no ensino médio $(39,83 \%)$, fizeram cursos pré-vestibulares $(57,76 \%)$ e provêm de famílias de classe média-alta, com renda entre $\mathrm{R} \$ 1.201,00 \mathrm{e}$ $\mathrm{R} \$ 2.400,00$ (22,13\%). Esse perfil, divulgado pela Comissão Permanente para os Vestibulares (Comvest) da instituição, praticamente, não mudou em relação aos cinco anos anteriores. (COMVEST, 2006)

Os estudantes que prestam o vestibular da Unicamp ou que ingressam na pós-graduação são procedentes de todas as regiões do Brasil, bem como de outros países, sobretudo da América do Sul, o que representa risco e vulnerabilidade a uma série de doenças endêmicas, além daquelas de alta prevalência global, a partir do momento que todos eles se reúnem num universo restrito de 55 mil metros quadrados. Além disso, deve ser levado em conta o fato de os estudantes serem jovens e de baixa renda - haja vista o processo seletivo por que passam anualmente -, o que os expõe a uma série de riscos. Presume-se um alto índice de SUS-dependência nesse ambiente, haja vista a impossibilidade de pagamento de convênios médicos. Embora seja uma população bem esclarecida, não se pode descartar 
por isso a negligência por parte dos estudantes em relação à própria saúde: essa faixa etária está altamente exposta ao risco de drogadição, doenças mentais e sexualmente transmissíveis, gravidez indesejada e suas implicações para a saúde e para a vida acadêmica e pessoal.

Em meio a isso, este programa traz consigo uma proposta de educação em saúde calcada na participação, a qual não se resume a um processo de persuasão ou de transferência de informação, sendo também um processo de capacitação para transformar a realidade. A educação em saúde é uma prática social ou processo que contribui para a formação e desenvolvimento da consciência crítica das pessoas, a respeito de seus problemas de saúde e estimula a busca de soluções e a organização para a ação coletiva.

A sua história tem como característica um processo de mudanças, o qual se faz presente na própria nomenclatura desta área, denominada na segunda metade do século XIX de "educação higiênica", haja vista a associação à revolução bacteriana, passando à "educação sanitária", nos anos 20, com o desenvolvimento da saúde pública, enfatizando processos de prevenção, mas ainda norteada por uma orientação comportamentalista, finalmente na década de 70 à "educação em saúde", já incorporando os aspectos socioeconômico-culturais. (ROSSO; COLLET, 1999)

Existe a necessidade de pensar que a educação e a saúde não são mais como uma educação sanitarizada, localizada no interior da saúde ou ainda educação para a saúde, como se a saúde pudesse ser um estado que se atingisse depois de educado. É preciso recuperar a dimensão da educação e da saúde-doença e estabelecer as articulações entre esses dois campos e os movimentos sociais e percebê-las como práticas sociais articuladas. (MELO, 1987)

Assim, a atual educação em saúde interpreta os processos de saúde e doença a partir de vários referenciais e privilegia práticas participativas, considerando que educadores e a população têm saberes que se interagem, sendo unidos na "luta" por melhores condições de vida, superando os limites da ação sanitária para alcançar uma ação social de mudanças, comprometida com a promoção da saúde e o bem-estar geral. (SCHALL, 1996)

A definição de promoção da saúde é vista como o processo que possibilita a cada população avaliar a qualidade de vida que lhe é oferecida e atuar sobre ela para conseguir cada vez mais saúde. (FOSECI, 1990)

Sobre a qualidade da organização da saúde, o livro "Healthy people The surgeon general's report on health promotion and disease prevention" (1979) afirma que se uma nação quiser melhorar o nível de saúde de seus cidadãos, precisa reorganizar suas atuais prioridades relativas aos cuida- 
dos com a saúde para dar maior ênfase à prevenção das doenças e à promoção da saúde. (DENVER, 1988).

A Carta de Ottawa para a promoção da saúde, adotada durante a Primeira Conferência Internacional sobre Promoção de Saúde, declara que:

As condições e recursos fundamentais para a saúde são: a paz, a moradia, a educação, os alimentos, os insumos, um ecossistema estável, os recursos renováveis, a justiça social e a eqüidade. A melhoria do setor de saúde deve fundamentar-se de um modo firme nestes requisitos básicos. (WORLD HEALTH ORGANIZATION, 1986, p.1)

É fundamental que no processo de planejamento de ações educacionais no campo da saúde, profissionais e a população reflitam sobre os problemas com o qual defrontam, desenvolvam estratégias e ações compatíveis com os valores existentes e assumam abordagens filosóficas sobre a sociedade, o homem, a saúde, a doença, que venham, de fato, contribuir para a promoção efetiva do ser humano. (SCHALL; STRUCHINNER, 1995)

Entre as abordagens propostas para essa prática está a humanista ("o homem é arquiteto de si mesmo"), a comportamentalista (o homem é fruto do seu meio e o ambiente social dá forma e preserva o comportamento; a experiência é a base do conhecimento) e político-social (os seres humanos estão em constante interação com o meio, são agentes da transformação deste e sujeitos da sua própria educação). (SCHALL, 1995; STRUCHINNER, 1995, p. 84-105).

Entre os modelos propostos para a intervenção no meio está o de mudança de comportamento (o especialista acha, dentro de uma concepção biomédica, o que o cliente deve fazer; a prevenção se dá em nível primário [informação e prevenção], secundário [detecção e tratamento de doenças] e terciário [doenças terminais e crônicas]), o modelo de autofortalecimento (aprendizagem participativa, de orientação humanista), o modelo de orientação comunitária (o indivíduo é responsável pela própria saúde) e o de transformação social (mudança social através de movimentos coletivos organizados; as mudanças no nível das idéias requerem desmistificar e tornar acessível o conhecimento médico separando-se os argumentos científicos das considerações morais). (SCHALL, 1995; STRUCHINNER, 1995)

A educação em saúde faz parte de uma reformulação do sistema de saúde que extrapola o âmbito administrativo, a qual deve ser estendida ao melhoramento da relação entre instituição, profissional de saúde e usuários no afã de possibilitar a reeducação de ambos os agentes, o técnico e o usuário, tendo por referência o desenvolvimento da cidadania social e po- 
lítica e a busca da construção de sujeitos, com respeito à autonomia e à emancipação. (L'ABBATE; SMEKE; OSHIRO, 1992)

Conforme conceito do Centro de Criação de Imagem Popular - CECIP (2006), a educação em saúde é o

aprendizado das opções, dar ao indivíduo e à comunidade os critérios para escolher entre as alternativas possíveis e tomar decisões as mais saudáveis possíveis e tomar decisões mais saudáveis para seu próprio bem-estar. Todas as pessoas têm um potencial para mudanças de comportamento e estilos de vida, desde que compreendam as razões e os benefícios dessas mudanças.

Esse conceito está intimamente relacionado ao Sistema Único de Saúde (SUS), o qual tem como objetivo dar assistência à população baseada no modelo da promoção, proteção e recuperação da saúde. O SUS é uma nova formulação política e organizacional para o reordenamento dos serviços e ações de saúde estabelecida pela Constituição Federal de 1988. É um sistema único porque segue a mesma doutrina e os mesmos princípios organizativos em todo o território nacional, sob a responsabilidade das três esferas autônomas de governo federal, estadual e municipal. O sistema baseia-se nos princípios doutrinários de universalidade, eqüidade e integralidade. Universalidade define-se como a garantia de atenção à saúde por parte do sistema a todo e qualquer cidadão; direito de cidadania e dever do Estado. Eqüidade consiste em assegurar ações e serviços de todos os níveis de acordo com a complexidade que cada caso requeira. Por último, integralidade é o reconhecimento na prática de saúde que o ser humano é um ser integral, biopsicossocial, e deverá ser atendido com uma visão integral por um sistema de saúde também integral, voltado a promover, proteger e recuperar sua saúde. (MINISTÉRIO DA SAÚDE, 1990).

As atividades baseiam-se nos princípios do SUS de regionalização, hierarquização e participação dos cidadãos. A rede de serviços, organizada de forma regionalizada e hierarquizada, focada em um território repleto de necessidades de saúde como a Moradia da Unicamp, permite um conhecimento maior dos problemas de saúde da população da área delimitada, favorecendo ações de vigilância epidemiológica, sanitária, controle de vetores, educação em saúde, além das ações de atenção ambulatorial e hospitalar em todos os níveis de complexidade. A participação dos cidadãos envolve o dever das instituições oferecerem as informações e conhecimentos necessários para que a população se posicione sobre as questões que dizem respeito à sua saúde. (MINISTÉRIO DA SAÚDE, 1990). 
Faz parte das atividades a elaboração de um questionário estruturado para a realização de um censo na Moradia da Unicamp, a fim de avaliar inicialmente a saúde e o conhecimento dos moradores a respeito dos seguintes temas: vacinação, diabetes mellitus, hipertensão arterial, obesidade, sedentarismo, dislipidemia, dependência química, tuberculose, doenças sexualmente transmissíveis e comportamento sexual de risco, trauma e violência, epilepsia, anemia, saúde bucal, acuidade visual e saúde mental.

Quanto à vacinação, um dos temas tratados no programa, abordados no âmbito da atenção básica de saúde, pode-se traçar um pequeno histórico de seu surgimento entre as políticas da área. O Programa Nacional de Imunizações (PNI) foi introduzido em 1973 com o objetivo de controlar ou erradicar a poliomielite, o sarampo, a difteria, o tétano, a coqueluche e a tuberculose, mediante imunização sistemática, com a meta de atingir $100 \%$ de cobertura vacinal para o primeiro ano de vida (FUNASA, 1993). Apesar desses esforços, em 1988 a cobertura vacinal no país ainda era aquém da expectativa: $63 \%$ para a anti-sarampo, $62 \%$ para a tríplice bacteriana (tétano, difteria e coqueluche) e Sabin (antipoliomielite) e 61\% para a BCG (antituberculose) (FUNASA, 1994). Nos últimos anos houve melhora sensível. Em 2001, as estatísticas oficiais foram de 102,93\%; 96,73\%; 101,92\%; e 111,6\%, respectivamente (DATASUS, 2001). Entretanto, os valores acima de $100 \%$ põem em dúvida a confiabilidade dos dados. Não somente fatores relacionados com os usuários estão associados a níveis baixos de cobertura vacinal. Fatores estruturais relacionados aos serviços de saúde tais como retardo no agendamento das consultas, falta de consultas noturnas ou nos finais de semana, filas e tempo de espera também dificultam as vacinações. (LANNON, 1995)

Outro problema tratado neste trabalho é o diabetes mellitus, um problema de saúde pública no país dada a sua alta prevalência (estimada em $7,6 \%$ em 2003), a gravidade de suas complicações a longo prazo e o fato de estar acompanhada de hipertensão, obesidade e sedentarismo (DATASUS, 2006) Todos esses, inclusive o diabetes, são fatores de risco para doenças cardiovasculares, maior causa de mortalidade no Brasil (taxa de mortalidade específica de 153,45 por 100 mil habitantes em 2000) (DATASUS, 2006). Associado ao diabetes, à hipertensão e à obesidade está o conceito recente de síndrome metabólica, definido pela Organização Mundial de Saúde e pelo National Cholesterol Education Program's Adult Treatment Panel III (NCEP-ATP III) como sendo três ou mais dos seguintes sinais: 1) obesidade abdominal definida como circunferência abdominal maior que $102 \mathrm{~cm}$ para homens e $88 \mathrm{~cm}$ para mulheres; 2) trigliceridemia maior ou igual a $150 \mathrm{mg} / \mathrm{dL}$; 3) HDL-c menor que $40 \mathrm{mg}$ / 
dL em homens e $50 \mathrm{mg} / \mathrm{dL}$ em mulheres; 4) pressão arterial sistólica maior ou igual a $130 \mathrm{mmHg}$ e/ou pressão diastólica maior ou igual a $85 \mathrm{mmHg}$; e glicemia de jejum maior ou igual a $110 \mathrm{mmHg}$. Estudos em diferentes populações, como a mexicana, a norte-americana e a asiática, revelam prevalências elevadas da síndrome metabólica, dependendo do critério utilizado e das características da população estudada, variando as taxas de $12,4 \%$ a $28,5 \%$ em homens e de $10,7 \%$ a $40,5 \%$ em mulheres. Daí está a importância da avaliação da glicemia, da trigliceridemia, da circunferência abdominal e da pressão arterial em se tratando de saúde pública (SOCIEDADE BRASILEIRA DE HIPERTENSÃO, 2005).

Com relação à dependência química, o tema tem relevância uma vez que o consumo mundial de drogas e/ou substâncias psicoativas está aumentando (UNODC, 2004). O abuso e a dependência de drogas ameaçam os valores políticos, econômicos e sociais. Além de contribuir para o crescimento dos gastos com tratamento médico e internação hospitalar, eleva os índices de acidentes de trânsito, de violência urbana e de mortes prematuras. (CARLINI-COTRIM, 2000).

Estima-se uma prevalência de uso de "drogas ilícitas" de 38,1\% na vida, 26,3\% nos últimos 12 meses e 18,9\% no último mês entre universitários de cursos da área de ciências biológicas. O álcool e o tabaco foram identificados como as substâncias mais consumidas, enquanto o uso de "drogas ilícitas" é maior entre alunos do sexo masculino e maior ainda entre os que moram sem a família. A alta prevalência do uso nos últimos 12 meses foi de $82,3 \%$ de álcool, 29,6\% de tabaco e 30,6\% de "drogas ilícitas". (ANDRADE, 1997)

A tuberculose é outro problema de saúde pública no país, dada a sua elevada incidência (44,57 casos por 100 mil habitantes em 2002), que se tem mantido relativamente constante ao longo dos últimos anos, sobretudo após o surgimento da Aids e da multirresistência a antibióticos (OLIVEIRA, 2004). Com o intuito de mudar esse quadro foi lançado pelo Ministério da Saúde, em 1999, o Plano Nacional de Controle da Tuberculose (PNCT), definindo a doença como questão de prioridade entre as políticas governamentais de Saúde Pública. Um conjunto de ações descentralizadas, sob responsabilidade de diferentes setores do Ministério da Saúde e das Secretarias de Estado e Municipais de Saúde, estabeleceu diretrizes e fixou metas para o alcance dos objetivos do plano: 1) implementar a cobertura do PCNT em 100\% dos municípios; 2) diagnosticar pelo menos $92 \%$ dos casos esperados e tratar com sucesso, ao menos $85 \%$ deles; e 3 ) reduzir a incidência da doença em $50 \%$ e a sua mortalidade em dois terços. (FUNASA, 2000) 
Também apresenta relevância no âmbito da saúde pública e de forma especial em meio a uma população jovem o tema comportamento sexual de risco, associado às doenças sexualmente transmissíveis, a gravidez indesejada e a consequiente prática de abortos, mortalidade materna e morbimortalidade reprodutiva (BERAL, 1979). A primeira ação governamental a respeito de planejamento familiar data de 1983, ano do lançamento do Programa de Assistência Integral à Saúde da Mulher (Paism) pelo Ministério da Saúde (OSIS, 1998). Entretanto somente a Constituição Federal de 1988 tornou o planejamento familiar um direito do cidadão. A lei n. ${ }^{\circ} 9.263$ de 12 de janeiro de 1996 regulamenta o parágrafo $7 .{ }^{\circ}$ do artigo 226 da Constituição, definindo o planejamento familiar como sendo um conjunto de ações de regulação da fecundidade que garante direito igual de constituição, limitação ou aumento da prole pela mulher, pelo homem ou pelo casal, dentro de uma visão de atendimento global e integral à saúde, sendo proibida a utilização de ações para qualquer tipo de controle demográfico (MINISTÉRIO DA SAÚDE, 1997). Estima-se que no Brasil apenas 55,4\% das mulheres em idade reprodutiva (15-49 anos) fazem uso de algum método contraceptivo. (BENFAM, 1997).

As doenças sexualmente transmissíveis, apesar dos avanços do tratamento, continuam altamente prevalentes no país, devido a uma série de fatores, entre os quais figuram a rotatividade desregrada de parceiros e a falta de orientação adequada para as pessoas trabalharem essas questões em relação a si e aos outros. O nome DST reúne diversas doenças com as mais variadas fisiopatologias e, portanto, os mais diversos efeitos na saúde do paciente, variando da morbidade à mortalidade (ELUCIR, 1991).

No Brasil não existem dados estatísticos precisos que revelem a real magnitude, uma vez que os dados disponíveis são de estudos isolados e das doenças de transmissão sexual, apenas a sífilis congênita e a Aids são de notificação compulsória: são 779 casos da primeira e 12.405 desta última doença notificados de 1980 a 1990 (MINISTÉRIO DA SAÚDE - BOLETIM EPIDEMIOLÓGICO AIDS, 1990 e DST, 1989). Estima-se que em 2003 houve no país 843.300 casos de sífilis, 775.180 de gonorréia, 1.500 .490 de infecção por Chlamydia sp., 89.110 de herpes genital e 137.080 de HPV (PN-DST/AIDS, 2003). Prevalentes, essas doenças estão associadas a complicações graves: a sífilis provoca graves sequielas neurológicas e cardiovasculares na sua forma terciária, além de resultar em malformações e retardo do desenvolvimento neuropsicomotor em caso de infecção congênita; a gonorréia e a infecção por Chlamydia sp. em mulheres estão associadas a doença inflamatória pélvica (grande causa de dor pélvica crônica, infertilidade e gravidez ectópica tubária); e o HPV está 
associado ao câncer de colo de útero (MINISTÉRIO DA SAÚDE, 1999). A alta prevalência em nosso meio de câncer de colo de útero (incidência estimada para 2006 de 20 casos por 100 mil habitantes) e de câncer de mama (52 casos por 100 mil habitantes) justifica questionar a população feminina da moradia sobre a realização de exames preventivos, tais como a citologia oncológica (Papanicolaou) a partir dos 23 anos ou quando do início da atividade sexual e o auto-exame das mamas a partir dos 20 anos de idade, conforme recomendação da Organização Mundial de Saúde. (INCA, 2006)

Trauma e violência é um tema relevante no âmbito da saúde pública em vista da grande morbimortalidade que representa no país. A taxa de mortalidade por causas externas em 2000 foi de 69,71 por 100 mil habitantes, o que coloca essa categoria como a segunda maior causa de morte no país, atrás somente das doenças cardiovasculares (DATASUS, 2006). As causas externas envolvem acidentes de trânsito (taxa de 17,46 por 100 mil), homicídios $(26,75$ por 100 mil) e suicídios (3,99 por 100 mil).

Outra doença que merece grande importância, sobretudo em se tratando de conscientização, devido ao estigma associado à condição, é a epilepsia, enfermidade neurológica grave de maior prevalência no mundo (MIN; SANDER, 2003). No Estado de São Paulo a prevalência estimada é de 11,9 por 1.000 habitantes. (MARINO JR.; CUKIERT; PINHO, 1986).

A anemia, caracterizada por níveis de hemoglobina menores que 11 g/dL, também será abordada no questionário dada a sua alta prevalência, sobretudo em crianças. Segundo estudo de Torres et al., 1994, a prevalência de anemia avaliada em 63 municípios do Estado de São Paulo foi de 59,1\% na faixa etária de seis a 23 meses. Uma série histórica no município de São Paulo que abrange a faixa etária de zero a cinco anos relata uma prevalência de 46,9\% (MONTEIRO; SZARFARC; MONDINI, 2000).

A saúde bucal também é um tema relevante para a saúde pública, devido à elevada prevalência de doenças relacionadas. Conforme dados do Projeto SB Brasil - Levantamento das Condições de Saúde Bucal da População Brasileira, que envolveu 108.921 pessoas, realizado entre 2002 e 2003 pelo Ministério da Saúde, pelo Conselho Federal e pela Associação Brasileira de Odontologia, a prevalência de cárie dentária é de $27 \%$ na faixa etária de 18 a 36 meses e de $60 \%$ em crianças de zero a cinco anos de idade. A cárie tem um avanço proporcional à idade: o índice de CPO (dentes cariados, perdidos e obturados) é de 2,8 nas crianças de 12 anos, 6,2 nos adolescentes, 20,1 nos adultos e 27,8 nos idosos. Apenas $55 \%$ de todos os adolescentes de 18 anos têm todos os dentes. Mais de $28 \%$ dos adultos não têm nenhum dente funcional. Menos de $22 \%$ da população 
adulta e $8 \%$ da idosa possuem gengivas sadias. Esses números estão aquém do preconizado pela OMS: CPO menor que 3, proporção de adolescentes com todos os dentes de $80 \%$, proporção de crianças de cinco anos que nunca tiveram cárie de $50 \%$.

A baixa acuidade visual é também um problema de saúde prevalente no Brasil e merece atenção especial na avaliação básica, sobretudo em se tratando de crianças. Conforme dados da Organização Mundial de Saúde, há 1,5 milhões de crianças no mundo com acuidade visual compatível com a cegueira infantil (menor que 20/400 no melhor olho). A prevalência varia de 0,3 a 1,2 por 1.000 crianças em países industrializados e muito pobres, respectivamente.

As doenças da tireóide têm importância no âmbito da saúde básica devido principalmente ao aumento da sensibilidade dos métodos de dosagem de TSH, o que tem permitido diagnosticar disfunção tireoidiana mesmo na ausência de doença clínica. O hipotireoidismo mesmo subclínico é um fator de risco para doença cardiovascular em mulheres idosas. (BENSEÑOR, 2002).

Grande relevância no questionário merece a saúde mental, dada a alta prevalência de transtornos de ordem psíquica no mundo. A ansiedade, um dos mais frequientes é prova disso: na Espanha a prevalência é de 13,8\%, no Canadá, 19,2\% e nos Estados Unidos, 21,8\%. No Brasil é a mais prevalente das doenças mentais. É freqüente ainda a co-morbidade entre transtorno de ansiedade e depressão e transtorno de personalidade. (BOTEGA, 2002)

A depressão, doença que pode comprometer a qualidade de vida tanto ou mais que a artrite reumatóide e o diabetes, é igualmente de grande frequiência: ao longo da vida, uma em cada 20 pessoas é acometida por episódio depressivo moderado ou grave. Estima-se que 15\% dos deprimidos graves cometam suicídio. (BOTEGA, 2002)

Portanto, fica assim justificada a inclusão desses problemas de saúde no questionário, o que poderá amparar a intervenção e permitir a conscientização dos moradores a respeito de sua própria saúde e de um investimento pessoal de cada estudante em prol da melhoria do ambiente e do status de saúde coletiva.

\section{JUSTIFICATIVA}

Todas as ações previstas no programa se justificam pela importância dos temas de saúde pública que serão tratados e também devido à vulnerabilidade dos moradores a uma série de problemas cuja abordagem 
pode ser feita em nível básico, por meio de intervenções simples, entre as quais conscientização, apenas. Os dados obtidos, analisados descritivamente, embasarão essas ações, além de serem submetidos a publicação, uma vez que não há na literatura da área de saúde um trabalho semelhante.

\section{OBJETIVO GERAL}

As atividades têm como objetivo inicial a realização de um censo acerca da saúde dos moradores por meio de um questionário estruturado (vide anexo), o qual, embora não tenha sido testado previamente, engloba assuntos abordados no nível primário do Sistema Único de Saúde, isto é, a porta de entrada da rede pública e principal braço do SUS em se tratando de promoção de saúde.

Tendo esse critério em vista, especial importância nos 20 itens foi dada à vacinação e às doenças de elevada prevalência e incidência no Brasil, tais como tuberculose, diabetes mellitus e síndrome metabólica, hipertensão arterial, tabagismo, alcoolismo, drogadição, doenças sexualmente transmissíveis, doenças bucais, doenças mentais, bem como os antecedentes nosológicos dos moradores.

Após esse estudo inicial, cujos dados serão trabalhados de forma descritiva, a equipe de projetos do PME terá em mãos um instrumento para guiar um programa de intervenção, o qual tomará forma de uma feira de saúde, isto é, um evento de utilidade pública, gratuito, portanto sem fins lucrativos, realizado nas dependências da Moradia da Unicamp, podendo englobar, conforme a disponibilidade de verbas e recursos, a comunidade das adjacências. O evento é o passo inicial de um trabalho de sensibilização dos moradores que deverá ser realizado de forma contínua, através de vigilância em saúde realizada pela equipe de projetos do PME, sob orientação de profissionais e estudantes da área de saúde.

\section{OBJETIVOS ESPECÍFICOS}

Os objetivos específicos de todas essas atividades são: 1) avaliar o conhecimento e atenção que cada morador tem em relação à própria saúde, bem como suas necessidades de saúde; 2) conscientizar e capacitar a comunidade na prevenção de doenças e manutenção da saúde; 3 ) instituir uma política de educação em saúde que desenvolva parcerias com a comunidade adjacente do distrito de Barão Geraldo; 4) fortalecer e estimular experiências bem-sucedidas da educação continuada; e 5) garantir espaço para a educação continuada de acordo com a necessidade da população. 


\section{HIPÓTESES}

Embora não haja dados na literatura a respeito de estudos semelhantes em moradias estudantis, espera-se, ao final do trabalho, encontrar um perfil socioeconômico condizente com a SUS-dependência e uma prevalência de agravos e doenças semelhantes aos números do Brasil, haja vista se tratar de um censo que, teoricamente, engloba os alunos de renda mais baixa da Unicamp, advindos dos mais diversos Estados do país. Por se tratar de alunos de nível universitário, espera-se um conhecimento razoável a respeito de saúde básica, sem que isso possa representar total aplicação dos conceitos aprendidos; necessidades de saúde semelhantes às da população brasileira correlata; consciência a respeito da prevenção de doenças e manutenção da saúde não vista, com freqüência, na prática. Esse programa de atividades introduzirá, portanto, na população o conceito de uma política de educação em saúde que desenvolva parcerias com a comunidade adjacente do distrito de Barão Geraldo; o estímulo de experiências bem-sucedidas de educação continuada e a garantia de espaço para a educação continuada de acordo com a necessidade da população.

\section{SUJEITOS E MÉTODOS}

As atividades terão como ponto de partida um estudo epidemiológico transversal e descritivo o qual dará base a uma feira de saúde. Para a realização das atividades, deverão ser firmadas parcerias entre o PME e outras unidades da Unicamp, sobretudo da área da saúde, bem como a iniciativa privada regional e o governo municipal, estadual e/ou federal. O cronograma das atividades será planejado conforme a formação de parcerias, em conjunto com as entidades participantes, entretanto o censo e a análise dos resultados têm previsão de durar um ano, a partir do primeiro semestre de 2007 (vide quadro 1).

As atividades têm como público-alvo, a princípio, todos os moradores do PME, contudo, conforme a disponibilidade de parcerias e verbas, a atenção poderá ser estendida também à população das adjacências, mais precisamente do distrito de Barão Geraldo, em Campinas (SP). Os moradores do PME, cerca de 1.000 pessoas, englobam uma faixa etária heterogênea, de ambos os sexos (em proporção desconhecida), uma vez que se trata de estudantes de graduação e pós-graduação (adolescentes e adultos), algumas vezes casados, pais ou mães de crianças, que também dividem espaço com os alunos da universidade. Se acaso não for possível avaliar todos os moradores, não haverá critérios de inclusão e exclusão na amostragem. 
As atividades a serem realizadas no evento dependerão também da consecução de recursos e verbas e da avaliação da demanda por meio do censo; entretanto, a priori, tendo em vista a abordagem em nível primário, atenção especial será dada à aferição de pressão arterial e glicemia, antropometria, cálculo de IMC e circunferência abdominal, trigliceridemia, aferição de acuidade visual, bem como distribuição de preservativos, materiais demonstrativos e panfletos explicativos sobre temas de saúde, exibição de vídeos e realização de palestras. Caso necessário, encaminhamentos a outros serviços de saúde serão realizados.

As atividades de educação em saúde, a partir da feira de saúde, conforme a disponibilidade de verbas e outros recursos, deverão adquirir caráter contínuo, com uma abordagem político-social, dentro de um modelo de orientação comunitária e de transformação social, tomando o caráter de atividades de vigilância, educação e ações de prevenção das quais deverão participar também a população-alvo, segundo a metodologia da pesquisa-ação, a qual respeita a autonomia da população-alvo, a qual se torna agente e sujeito crítico capaz de assumir o compromisso da construção de uma nova realidade que vá ao encontro de seus anseios. Portanto, o papel do pesquisador, deixa o caráter paternalista para assumir uma posição moderadora, com intuito de sensibilizar o público para a importância da saúde coletiva em um ambiente vulnerável a vários problemas que podem ser combatidos com educação.

Quadro 1: Cronograma

\begin{tabular}{|c|c|c|c|c|c|c|c|c|c|c|c|c|}
\hline Etapas & $\begin{array}{c}1^{\circ} \\
\text { mês }\end{array}$ & $\begin{array}{c}2^{\circ} \\
\text { mês }\end{array}$ & $\begin{array}{c}3^{\circ} \\
\text { mês }\end{array}$ & $\begin{array}{c}4^{\circ} \\
\text { mês }\end{array}$ & $\begin{array}{c}5^{\circ} \\
\text { mês }\end{array}$ & $\begin{array}{c}6^{\circ} \\
\text { mês }\end{array}$ & $\begin{array}{c}7^{\circ} \\
\text { mês }\end{array}$ & $\begin{array}{c}8^{\circ} \\
\text { mês }\end{array}$ & $\begin{array}{c}9^{\circ} \\
\text { mês }\end{array}$ & $\begin{array}{c}10^{\circ} \\
\text { mês }\end{array}$ & $\begin{array}{c}11^{\circ} \\
\text { mês }\end{array}$ & $\begin{array}{c}12^{\circ} \\
\text { mês }\end{array}$ \\
\hline 1 & $\mathrm{X}$ & $\mathrm{X}$ & $\mathrm{X}$ & $\mathrm{X}$ & $\mathrm{X}$ & $\mathrm{X}$ & & & & & & \\
\hline 2 & & & & & & & $\mathrm{X}$ & $\mathrm{X}$ & $\mathrm{X}$ & $\mathrm{X}$ & $\mathrm{X}$ & \\
\hline 3 & & & & & & & & & & $\mathrm{X}$ & $\mathrm{X}$ & $\mathrm{X}$ \\
\hline
\end{tabular}

Observações: etapa 1: realização do censo; etapa 2: análise dos resultados e preparação para apresentação e publicação dos dados; etapa 3: apresentação dos resultados à comunidade universitária e consecução de recursos para continuidade do projeto.

\section{ASPECTOS ÉTICOS DA PESQUISA}

Os responsáveis pela pesquisa, uma vez que as atividades envolvem a abordagem de dados socioeconômicos, bem como a situação e o conheci- 
mento acerca da própria saúde, de cerca de 1.000 moradores - entre os quais figuram alunos de graduação e pós-graduação, menores e maiores de 18 anos, e parentes, inclusive crianças - estão comprometidos, desde a sua concepção, com o sigilo de todas as informações que forem coletadas.

A população a ser estudada, a princípio todas as pessoas que habitam o Programa de Moradia Estudantil da Unicamp, será identificada apenas pelas iniciais, se acaso concordar com os termos da pesquisa explicitados em termo de consentimento livre e esclarecido, de acordo com a resolução do Conselho Nacional de Saúde n. ${ }^{\circ} 196$ de 28 de outubro de 1996, na qual estão fundamentadas todas as ações desta pesquisa.

Portanto, este projeto está embasado nos princípios da Bioética - autonomia, beneficência, não-maleficência e justiça, uma vez que pretende ser claro em relação aos seus objetivos diante da população-alvo e respeitar a decisão desta de participar ou não do projeto, além de defender em sua vulnerabilidade grupos como crianças, as quais serão representadas pelos responsáveis legais. Os trabalhos serão realizados ponderando riscos e benefícios, evitando prováveis danos morais, razão pela qual este projeto se compromete a indenizar a parte afetada. O benefício obtido será um acompanhamento da saúde, de forma integral, em nível primário e/ou mais complexo, por meio de intervenções tais como feiras de saúde, educação e encaminhamentos para especialidades, se necessário. Comprometido com o sigilo, este também prima pela não-maleficência, justiça e eqüidade, já que pretende não excluir nenhum dos moradores, e sim incluir todos eles nesta pesquisa-ação, sem fins lucrativos, voltada apenas a fins sócio-humanitários.

Não estão previstos coleta de material biológico nem uso de placebo ou medicamentos em fase de pesquisa clínica. O sujeito não será remunerado de forma alguma para participar da pesquisa nem alocado em grupos para experimentação.

Fundamentados na resolução 196/96, o projeto foi submetido ao e aprovado pelo Comitê de Ética em Pesquisa da Faculdade de Ciências Médicas da Universidade Estadual de Campinas. 


\section{Anexo}

QUESTIONÁRIO DE AVALIAÇÃO DA SAÚDE DO MORADOR

PARTE I: IDENTIFICAÇÃO

DATA: SE ALUNO, REGISTRO ACADÊMICO:

NOME (INICIAIS):

CASA (MORADIA): SEXO: DATA DE NASCIMENTO: .. $/$. . . . . .

NATURALIDADE:

PROCEDÊNCIA (MORADIAS ANTERIORES):

ETNIA:( ) caucasóide; ( ) nigróide; ( ) oriental; ( ) indígena; ( ) outras, qual?

ESTADO CIVIL:

PROFISSÃO ATUAL (SE FOR O CASO, TAMBÉM AS ANTERIORES):

CURSO? SEMESTRE (PERÍODO)?

RENDA PESSOAL: ( ) até R\$200,00; ( ) R\$201,00-R\$500,00; ( ) R\$501,00$R \$ 1.000,00$; ( ) $R \$ 1.001,00$ - $R \$ 3.000,00$; ( ) $R \$ 3.001,00$ - $R \$ 5.000,00$; ( ) mais que $R \$ 5.000,00$.

RENDA FAMILIAR MENSAL: ( ) até R\$200,00; ( ) R\$ 201,00-R\$500,00; ( ) R\$ $501,00-R \$ 1.000,00 \quad$ ( ) $R \$ 1.001,00-R \$ 3.000,00$; ( ) $R \$ 3.001,00-R \$ 5.000,00$; ( ) mais que $\mathrm{R} \$ 5.000,00$.

POSSUI CONVÊNIO MÉDICO: ( ) SIM; ( ) NÃO.

EM CASO DE CRIANÇA OU PESSOA INCAPACITADA DE RESPONDER AO QUESTIONÁRIO, INFORMANTE:

PARTE II: AVALIAÇÃO DA SAÚDE

\section{II - 1) ANTECEDENTES PESSOAIS}

II - 1.1) COBERTURA VACINAL

1) VACINAÇÃO NA INFÂNCIA: Recebeu as vacinas seguintes na infância? BCG (tuberculose) - ( ) SIM, quantas doses? ou ( ) NÃO ou ( ) NÃO SABE; hepatite B - ( ) SIM, quantas doses?____ ou ( ) NÃO ou ( ) NÃO SABE; DPT ou tríplice bacteriana (tétano, difteria e coqueluche) - ( ) SIM, quantas doses? ou ( ) NÃO ou ( ) NÃO SABE; tetravalente (DPT + Haemophilus influenzae tipo B [Hib], somente a partir da década de 90) - ( ) SIM, quantas doses? ou ( ) NÃO ou ( ) NÃO SABE; rotavírus (somente a partir de 2006) - ( ) SIM, quantas doses? ou ( ) NÃO ou ( ) NÃO SABE; Sabin (poliomielite ou paralisia infantil) - ( ) SIM, quantas doses? ou ( ) NÃO 
ou ( ) NÃO SABE; MMR ou SRC (sarampo, caxumba e rubéola ou tríplice viral) ( ) SIM, quantas doses? ou ( ) NÃO ou ( ) NÃO SABE; febre amarela - ( ) SIM, quantas doses? ou ( ) NÃO ou ( ) NÃO SABE; DT ou dupla adulto (tétano e difteria, a partir dos 7 anos de idade) - ( ) SIM, quantas doses? ou ( ) NÃO ou ( ) NÃO SABE; outras (pneumococo [heptavalente ou pneumo-23], gripe, varicela-catapora, hepatite A)? - ( ) SIM, qual (is)? quantas doses?

NÃO ou ( ) NÃO SABE. ou ( )

VACINAÇÃO EM ADULTOS? Sabia que os adultos também precisam receber vacinação prevista em calendário do Ministério da Saúde? ( ) SIM ou ( ) NÃO.

VACINAS: Recebeu essas vacinas? DT (dupla adulto, tétano e difteria, conhecida como antitetânica) - ( ) SIM, quantas doses? ou NÃO ou NÃO SABE; a última dose foi há mais de 10 anos? SIM ou ( ) NÃO ou ( ) NÃO SABE; febre amarela - ( ) SIM, quantas doses? ou ( ) NÃO ou ( ) NÃO SABE; a última dose foi há mais de 10 anos? ( ) SIM ou ( ) NÃO ou ( ) NÃO SABE; MMR ou SRC - ( ) SIM, quantas doses? ou NÃO ou NÃO SABE; outras (hepatite $B$, hepatite $A$, cólera, influenza, febre tifóide etc.) - ( ) SIM, quais? doses? ou NÃO ou NÃO SABE. Quando foi a última dose?

\section{II -1.2) ANTECEDENTES NOSOLÓGICOS}

2) PRESSÃO ARTERIAL: é hipertenso? - ( ) SIM ou ( ) NÃO ou ( ) NÃO SABE, em caso positivo, você se trata? Qual tratamento?

há casos de hipertensão arterial na família? - ( ) SIM ou ( ) NÃO ou ( ) NÃO $\mathrm{SABE}$, quem e com que idade? afere a PA com freqüência? - ( ) SIM ou ( ) NÃO. Suas refeições são ricas em sal de cozinha (cerca de $10 \mathrm{~g}$ ou mais de sal por dia)? - ( ) SIM ou ( ) NÃO.

3) DIABETES MELLITUS: é diabético? - ( ) SIM ou ( ) NÃO ou ( ) NÃO SABE; em caso positivo, você se trata? Qual tratamento? ? já aferiu a glicemia? - ( ) SIM ou ( ) NÃO, há casos de DM na família? - SIM ou ( ) NÃO ou ( ) NÃO SABE, quem e com que idade?

teve sede excessiva, quantidade excessiva de urina nas micções e perda inexplicável de peso nos últimos tempos? - ( ) SIM ou ( ) NÃO, há quanto tempo?

4) OBESIDADE: sabe qual é seu índice de massa corporal? - ( ) SIM ou ( ) NÃO, quanto? ____, sabe qual é o valor ideal para o IMC? - ( ) SIM, qual? ou ( ) NÃO, afere seu peso com freqüência? - ( ) SIM ou ( ) NÃO, já aferiu sua circunferência abdominal? - SIM ou ( ) NÃO, quanto $(\mathrm{cm})$ ? teve ganho ou perda de peso excessivo nos últimos tempos? - ( ) SIM ou ( ) NÃO, quantos kg/ tempo? Faz mais de três refeições por dia? - ( ) SIM ou ( ) NÃO. Tem alimentação rica em fibras ( 5 porções diárias de vegetais ou $=33 \mathrm{~g}$ desse alimento por dia)? - ( ) SIM ou ( ) NÃO. Come carne, feijão ou soja todos os dias? - ( ) SIM ou ( ) NÃO. 
5) ATIVIDADE FÍSICA: faz atividade física por no mínimo 30min/ 3 vezes por semana? - ( ) SIM ou ( ) NÃO, qual?

6) DISLIPIDEMIA: já fez exame de perfil lipídico (colesterol, triglicérides, HDL e LDL)? - SIM ou ( ) NÃO, teve alguma alteração? - ( ) SIM ou ( ) NÃO, qual? em caso positivo, você se trata? - ( ) SIM ou ( )

NÃO Qual tratamento?

7) DEPENDÊNCIA QUÍMICA: faz uso de cigarro? - ( ) SIM ( ) NÃO ou ( ) exfumante, cigarros/dia/por quantos anos fumou?, faz uso de bebidas alcoólicas? ( ) SIM ou ( ) NÃO ou ( ) ex-etilista, quais bebidas, quantidade e freqüência, faz ou fez uso de drogas ilícitas? - ( ) SIM ou ( ) NÃO, quais drogas, quantidade usada e freqüência?. Já tentou parar o uso de alguma dessas drogas? Como?

Conhece o ASPA (ambulatório voltado ao tratamento de dependência química) do Hospital das Clínicas da Unicamp? - ( ) SIM ou ( ) NÃO.

8) TEM DOENÇA CRÔNICA E/OU GENÉTICA OU JÁ TEVE DOENÇAS GRAVES (ASMA, DOENÇA CARDÍACA, PARALISIAS, DOENÇA RENAL CRÔNICA, LÚPUS, ARTRITE REUMATÓIDE, DOENÇA DE CROHN, RETOCOLITE ULCERATIVA, ESPONDILITE ANQUILOSANTE, FEBRE REUMÁTICA, ENTRE OUTRAS)? - ( ) SIM ou ( ) NÃO, qual (is)?

Em caso positivo, você se trata? Qual tratamento?

9) FOI VÍTIMA DE TRAUMA, VIOLÊNCIA E/OU PASSOU POR CIRURGIA? - ( ) SIM ou ( ) NÃO, qual (is)?

Apresenta seqüelas? - ( ) SIM ou ( ) NÃO Em caso positivo, você se trata? Qual tratamento? Sabe princípios de primeiros socorros em urgência e emergência? ( ) SIM ou ( ) NÃO. Gostaria de dominar mais esse assunto? - ( ) SIM ou ( ) NÃO.

10) EXISTE EM SUA FAMÍLIA HISTÓRIA DE DOENÇA GRAVE? - ( ) SIM ou ( ) NÃO, qual (is)?.

11) TEM HISTÓRICO DE EXPOSIÇÃO A AGENTES PREJUDICIAIS À SAÚDE NO TRABALHO (TRABALHOS REPETITIVOS, SUBSTÂNCIAS TÓXICAS, AGENTES FÍSICOS E BIOLÓGICOS)? - ( ) SIM ou ( ) NÃO, qual(is)?.

12) JÁ FOI SUBMETIDO À INTERNAÇÃO? - ( ) SIM ou ( ) NÃO, por quê?.

13) JÁ CONTRAIU TUBERCULOSE OU FICOU EXPOSTO A UM PACIENTE COM ESSA DOENÇA? - ( ) SIM ou ( ) NÃO. Em caso positivo, você se tratou ou vem se tratando? - ( ) SIM ou ( ) NÃO. Qual tratamento?

Abandonou tratamento(s)? - ( ) SIM ou ( ) NÃO. Já fez o teste tuberculínico (reação da pele do antebraço a antígenos da bactéria causadora da tuberculose)? - ( ) SIM ou ( ) NÃO, qual foi o resultado? . Já tomou isoniazida $30 \mathrm{mg}(10 \mathrm{mg} / \mathrm{kg})$ por seis meses (quimioprofilaxia)? - ( ) SIM ou ( ) NÃO. 
Há crianças em sua casa? - ( ) SIM ou ( ) NÃO. Já teve outras doenças infecciosas graves que tenha resultado em seqüelas e tratamento prolongado (p. ex. esquistossomose, dengue, paracoccidioidomicose, pneumonia [especialmente se mais de uma vez], entre outras)? - ( ) SIM ou ( ) NÃO. Qual (is)?

Sabe como contraiu a doença (forma de transmissão)? - ( ) SIM ou ( ) NÃO. Como?

14) TEM EPILEPSIA (recorrência de crises epilépticas em intervalo maior que 24 horas) ou crises epilépticas isoladas? - ( ) SIM ou ( ) NÃO. Passou por tratamento? - ( ) SIM ou ( ) NÃO. Qual?

Há casos de epilepsia na família?

15) JÁ TEVE ANEMIA? - ( ) SIM ou ( ) NÃO. Passou por tratamento? - ( ) SIM ou ( ) NÃO. Qual? Este-

ve relacionada à má alimentação? - ( ) SIM ou ( ) NÂO. Em caso de gestante, esta anemia ocorreu durante a gestação? - ( ) SIM ou ( ) NÃO. Foi na infância? - ( ) SIM ou ( ) NÃO. Foi na vigência de uma doença grave ou internação hospitalar? - ( ) SIM ou ( ) NÃO. A família apresenta casos ou traços genéticos de anemia falciforme? - ( ) SIM ou ( ) NÃO. A família apresenta casos ou traços genéticos de beta ou alfa-talassemia? - ( ) SIM ou ( ) NÃO. A família apresenta casos de doença de membrana de glóbulos vermelhos tais como esferocitose ou eliptocitose ou casos de retirada cirúrgica do baço? - ( ) SIM ou ( ) NÃO. A anemia estava relacionada a uso de medicamentos ou doenças como lúpus e artrite reumatóide? - ( ) SIM ou ( ) NÃO.

16) SAÚDE BUCAL? vai ao cirurgião-dentista a cada 6 meses? - ( ) SIM ou ( ) NÃO; está fazendo tratamento dentário? - ( ) SIM ou ( ) NÃO, qual? , escova os dentes diariamente (3 vezes ou mais) ? - ( ) SIM ou ( ) NÃO, faz uso diário de fio dental? - ( ) SIM ou ( ) NÃO. Usa prótese dentária? - ( ) SIM ou ( ) NÃO. Apresenta dentes cariados? - ( ) SIM ou ( ) NÃO. Quantos?___. Já perdeu dentes? - ( ) SIM ou ( ) NÃO. Quantos?____.Já passou por obturações dentárias? - ( ) SIM ou ( ) NÃO. Quantas?___. Necessita de fazer uso de aparelho ortodôntico? - ( ) SIM ou ( ) NÃO. Apresenta ou já teve gengivite? - ( ) SIM ou ( ) NÃO. Tártaro? - ( ) SIM ou ( ) NÃO.

17) SAÚDE MENTAL? já ouviu falar do Sappe (Serviço de Apoio Psiquiátrico e Psicológico ao Estudante da Unicamp)? - ( ) SIM ou ( ) NÃO.

Está passando ou já passou por um momento de extrema preocupação acerca de mais de dois assuntos por mais de seis meses e esses sintomas vêm acompanhados de extrema inquietação, palpitações (sensação de batimentos cardíacos), sudorese, agitação, alterações do sono? - ( ) SIM ou ( ) NÃO.

Está passando ou já passou por momentos de extrema tristeza quase inexplicável e falta de prazer em fazer coisas que antes agradavam por mais de duas semanas, o que vem acompanhado de alterações do peso, do apetite, do sono, idéias 
suicidas ou sentimentos de culpa excessiva, sem que isso esteja relacionado à perda de um ente querido? - ( ) SIM ou ( ) NÃO.

EM CASO DE GESTANTES: Este quadro de tristeza foi depois de um parto? - ( ) SIM ou ( ) NÃO.

Apresenta ou já apresentou algum transtorno do comportamento alimentar, tais como indução de vômitos após grandes refeições, negação ao ato de fazer refeições por preocupação excessiva com o próprio corpo associado a grandes perdas de peso em pouco tempo? - ( ) SIM ou ( ) NÃO.

18) ACUIDADE VISUAL: apresenta boa visão? - ( ) SIM ou ( ) NÃO; faz uso de óculos ou lentes de contato? - ( ) SIM ou ( ) NÃO; qual problema e qual lente usa (dioptrias ou graus)?

com os óculos ou lentes consegue enxergar bem? - ( ) SIM ou ( ) NÃO; nasceu com alguma anormalidade da visão (glaucoma congênito, catarata congênita)? ( ) SIM ou ( ) NÃO. Qual?

Já teve inflamações e infecções oculares (conjuntivite, esclerite, ceratite, uveítes, retinites)? - ( ) SIM ou ( ) NÃO. Qual doença (exemplo: toxoplasmose ocular, tracoma)?

Isso resultou em alteração da visão? - ( ) SIM ou ( ) NÃO. Já teve trauma ocular? - ( ) SIM ou ( ) NÃO. Isso resultou em alteração da visão? - ( ) SIM ou ( ) NÃO.

19) TIREÓIDE: já passou por exame laboratorial de função tireoidiana? - ( ) SIM ou ( ) NÃO.

já teve alguma doença da tireóide? - ( ) SIM ou ( ) NÃO. Hipertireoidismo?- ( ) SIM ou ( ) NÃO; hipotireoidismo? - ( ) SIM ou ( ) NÃO, nódulos (bócio, adenomas, tumores, tireoidites) - ( ) SIM ou ( ) NÃO.

20) COMPORTAMENTO SEXUAL: Tem atividade sexual? - ( ) SIM ou ( ) NÃO. Usa preservativo em todas as relações sexuais? - ( ) SIM ou ( ) NÃO. Casal usa método anticoncepcional que não preservativos? - ( ) SIM ou ( ) NÃO. Já teve doenças sexualmente transmissíveis (sífilis, gonorréia, HPV ou crista de galo, chato, tricomoníase, infecção da uretra ou canal da urina acompanhada ou não de dor em juntas e dor e vermelhidão ocular) ? - ( ) SIM ou ( ) NÃO. Casal já teve gravidez não planejada? ( ) SIM ou ( ) NÃO. Já fez sorologia para HIV? - ( ) SIM ou ( ) NÃO. O resultado foi positivo? - ( ) SIM ou ( ) NÃO. Lembra-se de relações sexuais desprotegidas e uso de objetos contaminados com secreções de outras pessoas? - ( ) SIM ou ( ) NÃO. Em caso positivo está fazendo tratamento? - ( ) SIM ou ( ) NÃO. Está obtendo controle da carga viral? - ( ) SIM ou ( ) NÃO. SOMENTE PARA MULHERES: Faz prevenção contra câncer de mama e colo de útero (Papanicolaou e auto-exame)? - ( ) SIM ou ( ) NÃO. Com que freqüência? 


\section{REFERÊNCIAS}

ANDRADE, A. G. et al. Uso de álcool e drogas entre alunos de graduação da Universidade de São Paulo (1996). REV. ABP- APAL, São Paulo, v. 19, n. 2, p. 53-9, 1997.

BENFAM (SOCIEDADE CIVIL BEM-ESTAR FAMILIAR NO BRASIL). Pesquisa Nacional sobre Demografia e Saúde 1996. Rio de Janeiro: BENFAM, 1997.

BENSEÑOR, Isabela. Screening for thyroid disorders in asymptomatic adults from Brazilian populations. Sao Paulo Med. J., São Paulo, v.120, n..5, p. 146-151, julho 2002.

BERAL, V. Reproductive Mortality. Br Med J, Londres , n. 2, p. 632-4, 1979.

BOTEGA, N.J. (Org.). Prática psiquiátrica no hospital geral:

interconsulta e emergência. Porto Alegre: Artmed, 2002. v. 1, p. 203, 252.

CARLINI-COTRIM, B., GAZAL-CARVALHO, C.; GOUVEIA, N. Comportamentos de saúde entre jovens estudantes das redes pública e privada da área metropolitana do Estado de São Paulo. Rev. Saúde Pública, São Paulo, vol.34, no.6, p.636-645, dez 2000.

CENTRO DE CRIAÇÃO DE IMAGEM POPULAR - CECIP. Disponível em: http://www.cecip.com.br/edu_saude.htm\#. Acesso em: 28 jul. 2006. COMISSÃO PERMANENTE PARA OS VESTIBULARES. Disponível em: www.comvest.unicamp.br. Acesso em: 28 jul. 2006.

COSTA, A. M. Desenvolvimento e implantação do PAISM no Brasil. In: GIFFIN, K; COSTA, S.H.(Orgs.). Questão da saúde reprodutiva. Rio de Janeiro: Editora FIOCRUZ; 1999. p. 319-336.

DATASUS - BANCO DE DADOS DO SISTEMA ÚNICO DE SAÚDE. Disponível em www.datasus.gov.br/datasus/datasus.php. Acesso em: 28 jul. 2006.

\section{DEVER, G.E.A. A epidemiologia na administração dos serviços de} saúde. Tradução de Luís Galvão Cesar et al. São Paulo: Pioneira, 1988. ELUCIR, G. et al. Doenças sexualmente transmissíveis: conceitos, atitudes e percepções entre coletores de lixo. Rev Saúde Pública, São Paulo, v. 25 n. 3, junho de 1991. 
FOCESI, G.E.A. Educação em saúde na escola: o papel do professor.

Rev Bras Saúde Escolar, São Paulo, v.1, n.2, p 4-5, 1990.

FUNDAÇÃO NACIONAL DE SAÚDE. Manual de normas de vacinação. Brasília, DF: Departamento de Operações, 1994.

FUNDAÇÃO NACIONAL DE SAÚDE. Manual de procedimento para vacinação. Brasília, DF: Departamento de Operações, 1993.

FUNDAÇÃO NACIONAL DE SAÚDE. Normas para o controle da tuberculose. 5.ed. Brasília: Ministério da Saúde, 2000.

INSTITUTO NACIONAL DO CÂNCER. Estimativa 2006 - Incidência de câncer no Brasil. Rio de Janeiro: Inca, 2005. Disponível em: www.inca.gov.br. Acesso em: 28 jul. 2006.

L'ABBATE, S; SMEKE, ELM; OSHIRO, JH. A educação em saúde como um exercício de cidadania. Saúde em Debate, São Paulo, n. 37, p. 81-85, 1992.

LANNON, C., et al. What mothers say about why poor children fall behind on immunizations - a summary of focus groups in North Carolina. Arch Pediatr Adolesc Med, Chicago, n. 149, p.1.070-5, 1995. MARINO JÚNIOR, R; CUKIERT, A; PINHO, E. Aspectos epidemiológicos da epilepsia em Säo Paulo: um estudo da prevalência. Arq. neuropsiquiatr, São Paulo, v. 44, n. 3, p. 243-54, set. 1986. MELO, JAC. Educação sanitária: uma visão crítica. Cadernos do Cedes-educação e saúde, São Paulo, n.4, p. 28-43, 1987.

MIN, L.L; SANDER, J.W.A.S. National demonstration project on epilepsy in Brazil. Arq Neuro-Psiquiatr., São Paulo, v. 61, n.1, p.153156, mar. 2003.

MINISTÉRIO DA SAÚDE. ABC do SUS - Doutrinas e Princípios. Brasília, DF, 1990.

MINISTÉRIO DA SAÚDE. Boletim epidemiológico Aids. Brasília, 3 (11) 1990.

MINISTÉRIO DA SAÚDE. Boletim Epidemiológico DST. Brasília, Ministério da Saúde, 1(1) 1989.

MINISTÉRIO DA SAÚDE. Controle das doenças sexualmente transmissíveis - DST, 1999. Disponível em: http://www.aids.gov.br/ assistencia/mandst99/man_dorpelvica.htm. Acesso em: 28 jul 2006. 
MINISTÉRIO DA SAÚDE. Portaria n. 144 de 20 de novembro de 1997. Diário Oficial da República Federativa do Brasil. Brasília, DF, 27 nov. 1997.

MINISTÉRIO DA SAÚDE. Programa ampliado de imunizações (PAI). Brasília, DF: Centro de Documentação, 1988.

MONTEIRO, C.A; SZARFARC, S.C; MONDINI, L. Tendência secular da anemia na infância na cidade de São Paulo (1984-1996). Rev. Saúde Pública, local, v. 34, n. 6, p.62-72, dez. 2000.

OLIVEIRA, H.B., MARIN-LEON, L; CARDOSO, J.C. Perfil de mortalidade de pacientes com tuberculose relacionada à comorbidade tuberculose-Aids. Rev. Saúde Pública, São Paulo, v. 38, n. 4, p.503510, ago. 2004.

OSIS, MJD. PAISM: um marco na abordagem da saúde reprodutiva no Brasil. Cad. Saúde Pública, Rio de Janeiro, n. 14 Supl, , p.25-32, 1998. PN-DST/Aids, 2003. Disponível em: www.portal.saude.gov.br/saude. Acesso em: 28 jul. 2006.

ROSSO, CFW; COLLET, N. Os enfermeiros e a prática de educação em saúde em município do interior paranaense. Revista Eletrônica de Enfermagem (on-line), Goiânia, v.1, n.1, out./dez, 1999. Versão on-line SB BRASIL. Levantamento das condições de saúde bucal da população brasileira. Ano V, jul./ago. 2004. Disponível em: http:// portal.saude.gov.br/portal/arquivos/pdf/manual_brasil_sorridente4.pdf. Acesso em: 28 jul. 2006.

SCHALL, VT. Debate in the paper by Briceño-León. Cad. Saúde Pública, Rio de Janeiro, v. 12, n.1, p. 18-19, jan./mar. 1996.

SCHALL, V. T.; STRUCHINER, M. Educação no contexto da epidemia de HIV/Aids: Teorias e tendências pedagógicas. In: CZERESNIA, D. et al. Aids, pesquisa social e educação. São Paulo: Hucitec 1995. p. 84105.

SISTEMA ÚNICO DE SAÚDE - SUS. Disponível em: http:// www.consaude.com.br/sus/indice.htm. Acesso em: 28 jul 2006.

SOCIEDADE BRASILEIRA DE HIPERTENSÃO, SOCIEDADE BRASILEIRA DE CARDIOLOGIA. SOCIEDADE BRASILEIRA DE ENDOCRINOLOGIA E METABOLOGIA et al. I Diretriz Brasileira de Diagnóstico e Tratamento da Síndrome Metabólica. Arq. Bras.

Cardiol., São Paulo, v. 84, supl.1, p. 3-28, abr. 2005. 
TORRES, M.A.A.; SATO, K; QUEIROZ, S.S. Anemia em crianças menores de dois anos atendidas nas unidades básicas de saúde no Estado de São Paulo, Brasil. Rev. Saúde Pública, São Paulo, v. 28, n. 4, p. 290294, ago. 1994. ISSN 0034-8910.

UNITED NATIONS OFFICE ON DRUGS AND CRIME - UNODC.

Global illicit drug trends 2004. New York (NY): United Nations, 2004.

UNIVERSIDADE ESTADUAL DE CAMPINAS (UNICAMP).

Disponível em: www.unicamp.br. Acesso em: 28 jul. 2006.

UNIVERSIDADE ESTADUAL DE CAMPINAS - PROGRAMA DE MORADIA ESTUDANTIL. Disponível em: http:// www.prg.unicamp.br/ moradia/apresentacao.html. Acesso em: 28 jul 2006.

WORLD HEALTH ORGANIZATION. Ottawa Charter for Health for Health Promotion. In: INTERNATION CONFERENCE ON HEALTH PROMOTION. Anais. Ottawa, 1986, p. 1. 